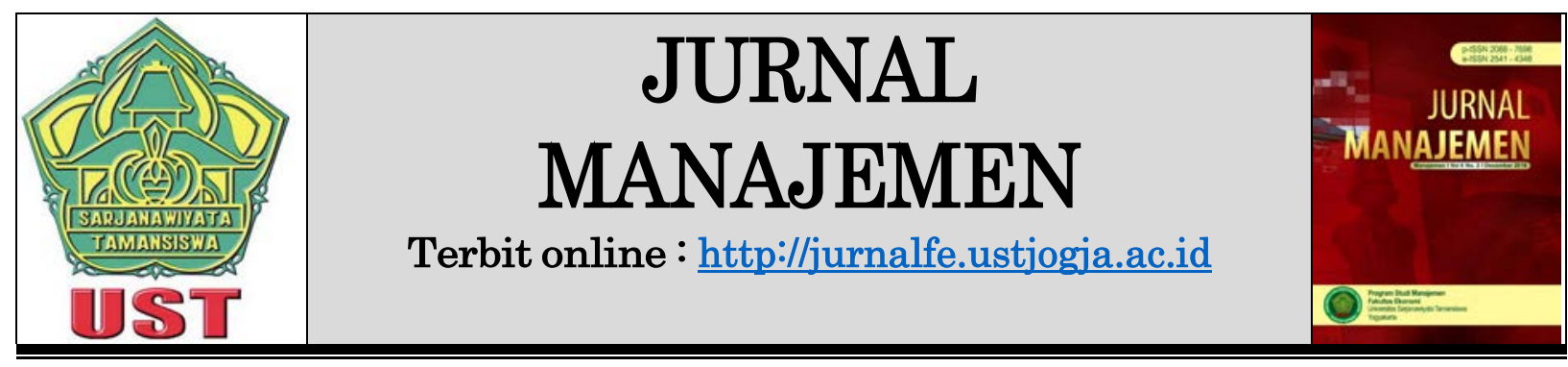

\title{
PENGARUH LINGKUNGAN KERJA DAN KOMPENSASI TERHADAP MOTIVASI KERJA SERTA DAMPAKNYA TERHADAP KINERJA KARYAWAN (Studi Kasus di Yogya Chicken Daerah Istimewa Yogyakarta)
}

\author{
Inayat Hanum Indriati
}

Universitas PGRI Yogyakarta

Korespondensi : inayathanum10@gmail.com

\begin{tabular}{lc}
\hline Informasi Naskah & Abstrak \\
\hline Diterima: & Human resources are central figures in organizations and \\
29 September & companies. Therefore, the existence of human resources within \\
Revisi: & the company must be considered by the leadership or \\
11 Oktober & management. The purpose of this study to determine the effect \\
Terbit: & of work environment and compensation on work motivation \\
16 Desember & and its impact on employee performance \\
\hline Kata Kunci: Work & This study uses a sample of employees Restaurant "Yogya \\
Environment, & Chicken" which amounted to 76 people. The analysis technique \\
Compensation, Work & used multiple linear regression analysis \\
Motivation, Employee & The results showed that: (1) simultaneously work \\
Performance & environment, and compensation have positive effect on work \\
& motivation of "Yogya Chicken" employee in DIY; (2) Partially \\
& work environment and compensation have positive effect on \\
& work motivation of "Yogya Chicken" employee in DIY; (3) \\
& Simultaneously work environment and compensation have \\
& positive effect on employee performance "Yogya Chicken" in \\
& DIY; (4) Partially, the working environment does not affect the \\
& performance of the employees of "Yogya Chicken" in DIY, while \\
the compensation has a positive effect on the performance of & the "Yogya Chicken" employee in DIY; (5) Work motivation has \\
a positive effect on employee performance "Yogya Chicken" in & DIYand (6) Work environment and compensation have positive \\
effect to work motivation and employee performance "Yogya & Chicken" in DIY.
\end{tabular}

\section{PENDAHULUAN}

Lingkungan kerja adalah segala sesuatu yang ada disekitar karyawan dan dapat mempengaruhi karyawan dalam menjalankan tugas yang diembannya. Lingkungan kerja perusahaan terbagi menjadi dua, yaitu lingkungan kerja fisik dan lingkungan kerja non 
fisik (Nitisemito dalam Nurani, 2013: 97). Lingkungan kerja yang kondusif membuat karyawan merasa nyaman dalam bekerja, sehingga mampu bekerja dengan baik. Dengan lingkungan kerja yang nyaman, maka target yang ditetapkan perusahaan akan tercapai, sehingga keuntungan perusahaan akan meningkat.

Kompensasi adalah semua hal yang diterima seorang pekerja sebagai balasan dari pekerjaan yang diberikannya. Kompensasi sendiri merupakan salah satu hal yang penting dalam menjaga stabilitas kerja karyawan. Kompensasi menurut Mondy \& Noe (1990) adalah setiap bentuk imbalan yang diterima oleh seseorang sebagai balasan atas kontribusinya terhadap organisasi. Menurut Werther \& Davis (1996) kompensasi adalah sesuatu yang diterima oleh seorang karyawan sebagai balasan dari karya yang diberikannya kepada organisasi. Kompensasi sendiri menurut Werther \& Davis (1996) di kelompokkan ke dalam dua bentuk umum, yaitu kompensasi langsung dan tidak langsung. Kompensasi langsung terdiri dari : a) gaji pokok dan upah b) insentif. Kompensasi tidak langsung meliputi asuransi kesehatan/jiwa, cuti berbayar dan dana pensiun. Lingkungan kerja yang nyaman dan kompensasi yang layak dapat mendorong motivasi kerja karyawan.

Motivasi menurut Robert Heller (1998:6) merupakan keinginan untuk bertindak. Sedangkan menurut Robert Kreitner dan Angelo Kinicki (2001:205) motivasi merupakan proses psikologis yang membangkitkan dan mengarahkan perilaku pada pencapaian tujuan atau goal-directed-behavior, sehingga dapat disimpulkan bahwa motivasi merupakan sebuah dorongan untuk melakukan atau tidak melakukan sebuah tindakan. Dengan motivasi kerja yang tinggi, diharapkan dapat meningkatkan kinerja karyawan. Kinerja menurut Mangkunegara (2011) adalah merupakan hasil kerja secara kualitas dan kuantitas yang dicapai oleh seseorang pegawai dalam melaksanakan tugasnya sesuai dengan tanggung jawab yang diberikan kepadanya.

\section{KAJIAN PUSTAKA DAN HIPOTESIS}

\section{Lingkungan Kerja}

Menurut (Nitisemito dalam Nuraini 2013:97) lingkungan kerja adalah segala sesuatu yang ada disekitar karyawan dan dapat mempengaruhidalammenjalankan tugas yang diembankan kepadanya misalnya dengan adanya airconditioner $(A C)$, penerangan yang memadai dan sebagainya. Menurut (Simanjuntak, 2003:39) lingkungan kerja dapat diartikansebagai keseluruhan alat perkakas yang dihadapi, lingkungan sekitarnyadimana seorang bekerja, metode kerjanya, sebagai pengaruh kerjanya baiksebagai perorangan maupun sebagai kelompok. Menurut (Nitisemito 2013:97) secara umum lingkungan kerja terdiri dari lingkungan kerja fisik dan lingkungan kerja non fisik.

\section{Faktor Lingkungan Kerja Fisik}

Faktor lingkungan kerja fisik adalah lingkungan yang berada disekitar pekerjaan itu sendiri, seperti:

a. Penerangan/cahaya di tempat kerja

b. Temperatur/suhu udara di tempat kerja

c. Suara/kebisingan di tempat kerja

d. Mutu Kualitas Udara

e. Tata letak ruang kerja

\section{Faktor Lingkungan Kerja Non Fisik}

Lingkungan kerja non fisik merupakan semua keadaan yang terjadi yang berkaitan dengan hubungan kerja. Lingkungan kerja non fisik terdiri atas: 
a. Hubungan kerja antara bawahan dengan atasan

b. Hubungan kerja antar karyawan

c. Tata kerja dan kemampuan menyesuaikan diri yang baik

d. Peningkatan Kualitas diri

\section{Kompensasi}

Mosley et all (1996:311) menyatakan bahwa "Compensation is providing employees with a financial payment as a reward for work performed and as motivator for future performance". Noe (2002:313) menyatakan bahwa "Compensation is the total of all rewards provided employees in return for their services". William B. Werther dan Keith Davis dalam (Hasibuan 2005:119) adalah apa saja yang seorang pekerja terima sebagai balasan dari pekerjaan yang diberikannya baik upah per jam atau gaji periodic didesain dan dikelola oleh bagian personalia. Kompensasi terbagi menjadi dua, yaitu:

1. Kompensasi Langsung

a. Berdasarkan pekerjaan dan kinerja yaitu Gaji Pokok dan Upah

b. Kompensasi berupa Penghasilan Tidak tetap seperti Bonus, Insentif dan Opsi Saham

2. Kompensasi Tidak Langsung

Berupa kondisi yang berhubungan dengan kinerja seperti : Asuransi kesehatan/jiwa, Cuti berbayar dan Dana pension.

\section{Motivasi Kerja}

Menurut Robbin (2008) motivasi adalah keinginan untuk berusaha sekuat tenaga untuk mencapai tujuan organisasi yang dikondisikan atau ditentukan oleh kemampuan usaha untuk memenuhi suatu kebutuhan individu.Banyak penulis kontemporer juga telah menetapkan konsep motivasi. Menurut Maslow (1996) motivasi adalah kekuatan energy seseorang yang dapat menimbulkan tingkat persistensi dan entusiasmenya dalam melaksanakan suatu kegiatan baik yang bersumber dari dalam diri individu itu sendiri (motivasi intrinsic) maupun dari luar individu (motivasi ekstrinsik).

Hodges dan Luthans dalam Handoko, Hani dkk (2005) menyatakan bahwa motivasi kerja merupakan proses psikologis melalui keinginan yang belum terpuaskan, yang diarahkan dan didorong ke pencapaian tujuan insentif. Menurut Luthans dalam Handoko dkk (2005) motivasi kerja merupakan proses dasar yang dimulai dengan adanya suatu kebutuhan (needs). Motivasi dapat diukur dengan menggunakan dasar teori motivasi dari Mc Clelland yaitu:

1) Kebutuhan prestasi (need for achievment): dorongan untuk melebihi, mencapai standar - standar, berusaha keras untuk berhasil.

2) Kebutuhan kekuatan (need for power): kebutuhan untuk membuat individu lain berperilaku sedemikian rupa sehingga mereka tidak akan berperilaku sebaliknya.

3) Kebutuhan hubungan (need for affiliation): keinginan untuk menjalin suatu hubungan antar personal yang ramah dan akrab.

\section{Kinerja Karyawan}

Handoko (2001) mendefinisikan kinerja sebagai proses melalui mana sebuah organisasi mengevaluasi atau menilai kinerja karyawan. Kamus bahasa Indonesia mengatakan bahwa kinerja mempunyai arti hasil yang telah di capai yang telah dilakukan, dikerjakan seseorang dalam melaksanakan kerja atau tugas. Menurut penelitian Bernadin (1993) dalam Crimson (2005), kinerja karyawan adalah perbandingan hasil kerja nyata karyawan dengan standar kerja yang telah ditetapkan oleh perusahaan. 
Beberapa indikator untuk mengukur sejauh mana pegawai mencapai suatu kinerja secara individual adalah sebagai berikut : kualitas, kuantitas, ketepatan waktu, efektifitas, kemandirian, dan komitmen organisasi.

1. Kualitas: tingkat dimana hasil aktifitas yang dilakukan mendekati sempurna dalam arti menyesuaikan beberapa cara ideal dari penampilan aktivitas ataupun memenuhi tujuan yang diharapkan dari suatu aktivitas.

2. Kuantitas: jumlah yang dihasilkan dalam istilah jumlah unit, jumlah siklus aktifitas yang diselesaikan.

3. Ketepatan waktu: tingkat suatu aktifitas diselesaikan pada waktu awal diinginkan, dilihat dari sudut koordinasi dengan hasil output serta memaksimalkan waktu yang tersedia untuk aktifitas lain.

4. Efektifitas: tingkat penggunaan sumberdaya manusia, organisasi dimaksimalkan dengan maksud menaikkan keuntungan atau mengurangi kerugian dari setiap unit dalam penggunaan sumberdaya.

5. Kemandirian: tingkat dimana seorang pegawai dapat melakukan fungsi kerjanya tanpa minta bantuan bimbingan dari pengawas atau meminta turut campurnya pengawas untuk menghindari hasil yang merugikan.

6. Komitmen organisasi: tingkat dimana pegawai mempunyai komitmen kerja dengan organisasi dan tanggung jawab pegawai terhadap organisasi.

\section{Hipotesis}

Hipotesis 1 : Lingkungan kerja, dan kompensasi secara simultan berpengaruh positif terhadap motivasi kerja karyawan "Yogya Chicken" di Daerah Istimewa Yogyakarta.

Hipotesis 2 : Lingkungan kerja dan kompensasi secara parsial berpengaruh positif terhadap motivasi kerja karyawan "Yogya Chicken" di Daerah Istimewa Yogyakarta.

Hipotesis 3 : Lingkungan kerja dan kompensasi secara simultan berpengaruh positif terhadap kinerja karyawan "Yogya Chicken" di Daerah Istimewa Yogyakarta.

Hipotesis 4 : Lingkungan kerja dan kompensasi secara parsial berpengaruh positif terhadap kinerja karyawan"Yogya Chicken" di Daerah Istimewa Yogyakarta.

Hipotesis 5 : Motivasi kerja berpengaruh positif terhadap kinerja karyawan "Yogya Chicken" di Daerah Istimewa Yogyakarta.

Hipotesis 6 : Lingkungan kerja, kompensasi dan motivasi kerja berpengaruh positif terhadap kinerja karyawan "Yogya Chicken" di Daerah Istimewa Yogyakarta

\section{METODE PENELITIAN}

Populasi dalam penelitian ini adalah karyawan Rumah Makan "Yogya Chicken". Teknik pengambilan sampel menggunakan metode proporsional stratified random sampling yaitu merupakan pemilihan sampel secara acak dimana dapat dilakukan dengan terlebih dahulu mengklasifikasikan suatu populasi ke dalam sub-sub populasi. Sampel kemudian dipilih dari setiap subpopulasi dengan metode undian. Menurut Hasan (2005) metode undian adalah metode sampling random sederhana yang prosesnya dilakukan dengan menggunakan pola pengundian. Untuk menentukan besarnya jumlah sampel dihitung dengan rumus Slovin, sebagai berikut:

$$
n=\frac{N}{1+N e^{2}}
$$


$\mathrm{n}=\mathbf{9 3} /\left(\left(1+93(0,05)^{\mathrm{t}} \mathbf{2}\right)=75,456\right.$ dibulatkan menjadi 76. karyawan.

Dengan demikian jumlah sampel dalam penelitian ini sebanyak 76 orang

Teknik analisis data menggunakan analisis regresi linier berganda dengan tiga persamaan yaitu:

Persamaan 1:

$$
\mathrm{Y}=B_{0}+B_{1} \mathrm{X}_{1}+B_{2} \mathrm{X}_{2}+\mathrm{e}
$$

Persamaan 2:

$$
Z=B_{0}+B_{3} X_{1}+B_{4} X_{2}+e
$$

Persamaan 3:

$$
\mathrm{Z}=B_{0}+B_{5} \mathrm{X}_{1}+B_{6} \mathrm{X}_{2}+B_{7} \mathrm{Y}+\mathrm{e}
$$

Dimana:

$$
\begin{aligned}
& \mathrm{Y} \quad=\text { motivasi kerja } \\
& \mathrm{Z} \quad \text { = kinerja karyawan } \\
& \text { B0 } \quad=\text { konstanta } \\
& B_{1}, B_{2}, B_{3}, B_{4}, B_{5}, B_{6}, B_{7} \quad=\text { koefisien regresi setiap variabel independent } \\
& \mathrm{X} 1 \quad=\text { lingkungan kerja } \\
& \mathrm{X} 2 \quad=\text { kompensasi } \\
& \text { e } \quad=\text { kesalahan (error) }
\end{aligned}
$$

\section{HASIL DAN PEMBAHASAN}

1. Analisis Regresi Model I

Model regresi persamaan I menganalisis pengaruh lingkungan kerja dan kompensasi terhadap motivasi kerja. Hasil uji F pada model regresi persamaan I dapat dilihat pada tabel berikut.

Tabel 1

Uji F Persamaan I

\begin{tabular}{|ll|r|r|r|r|r|}
\hline \multicolumn{1}{|l|}{ Model } & \multicolumn{1}{|c|}{$\begin{array}{c}\text { Sum of } \\
\text { Squares }\end{array}$} & df & \multicolumn{1}{c|}{$\begin{array}{c}\text { Mean } \\
\text { Square }\end{array}$} & F & \multicolumn{1}{c|}{ Sig. } \\
\hline 1 & Regression & 4754.534 & 2 & 2377.267 & 52.233 & $.000^{\mathrm{a}}$ \\
Residual & 3322.413 & 73 & 45.513 & & \\
Total & 8076.947 & 75 & & & \\
\hline
\end{tabular}

Sumber: data primer diolah, 2017

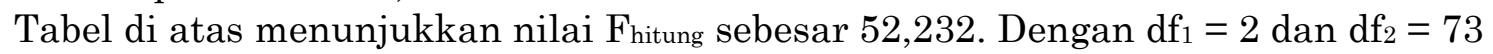

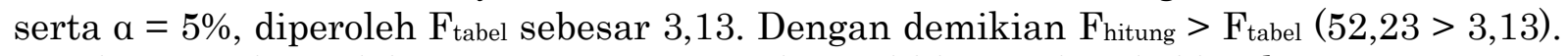
Hasil uji t pada model regresi persamaan I dapat dilihat pada tabel berikut. 
Tabel 2

Uji t Persamaan I

\begin{tabular}{|c|c|c|c|c|c|c|}
\hline \multirow{2}{*}{\multicolumn{2}{|c|}{ Model }} & \multicolumn{2}{|c|}{$\begin{array}{l}\text { Unstandardized } \\
\text { Coefficients }\end{array}$} & \multirow{2}{*}{$\mid \begin{array}{c}\begin{array}{c}\text { Standardized } \\
\text { Coefficients }\end{array} \\
\text { Beta }\end{array}$} & \multirow[b]{2}{*}{$\mathrm{t}$} & \multirow[b]{2}{*}{ Sig. } \\
\hline & & B & Std. Error & & & \\
\hline \multirow[t]{3}{*}{1} & (Constant) & 2.722 & 6.515 & & .418 & .677 \\
\hline & $\begin{array}{l}\text { lingkungan } \\
\text { kerja }\end{array}$ & .770 & .104 & .589 & 7.383 & .000 \\
\hline & kompensasi & .672 & .161 & .332 & 4.168 & .000 \\
\hline
\end{tabular}

Sumber: data primer diolah, 2017

Tabel di atas menunjukkan nilai ttabel variabel lingkungan kerja sebesar 7,383 dan kompensasi sebesar 4,168. Dengan df $=73$ dan $\alpha=5 \%$ diperoleh ttabel sebesar 1,99. Berikut ini analisis dari masing-masing variabel independen:

1. Pengaruh lingkungan kerja terhadap motivasi kerja

Hasil uji t menunjukkan bahwa thitung sebesar 7,383 dan nilai signifikansi sebesar 0,000 . Hasil tersebut menunjukkan bahwa nilai thitung $(7,383)>t_{\text {tabel }}(1,99)$ dan atau $p$ value $0,000<0,05$ maka dapat disimpulkan bahwa lingkungan kerja berpengaruh positif terhadap motivasi kerja.

2. Pengaruh kompensasi terhadap motivasi kerja

Hasil uji t menunjukkan bahwa thitung sebesar 4,168 dan nilai signifikansi sebesar 0,000 . Hasil tersebut menunjukkan bahwa nilai thitung $(4,168)>t_{\text {tabel }}(1,99)$ dan atau $p$ value $0,000<0,05$ maka dapat disimpulkan bahwa kompensasi berpengaruh positif terhadap motivasi kerja.

Berdasarkan kedua analisis di atas dapat disimpulkan bahwa lingkungan kerja dan kompensasi secara parsial berpengaruh positif terhadap motivasi kerja karyawan "Yogya Chicken" di Daerah Istimewa Yogyakarta, sehingga $\mathrm{H}_{2}$ diterima. Untuk mengetahui besarnya pengaruh variabel lingkungan kerja dan kompensasi terhadap motivasi kerja karyawan "Yogya Chicken" di Daerah Istimewa Yogyakarta dapat dilihat pada tabel di bawah ini.

Tabel 3

Hasil Uji Koefisien Determinasi

\begin{tabular}{|l|c|r|r|r|}
\hline Model & R & R Square & $\begin{array}{c}\text { Adjusted R } \\
\text { Square }\end{array}$ & $\begin{array}{c}\text { Std. Error of } \\
\text { the Estimate }\end{array}$ \\
\hline 1 & $.767 \mathrm{a}$ & .589 & .577 & 6.746 \\
\hline
\end{tabular}

Sumber: data primer diolah

Tabel di atas menunjukkan nilai koefisien determinasi $\left(\mathrm{R}^{2}\right)$ sebesar 0,589. Artinya pengaruh variabel lingkungan kerja dan kompensasi terhadap motivasi kerja karyawan sebesar 58,9\% sedangkan 41,1\% dipengaruhi oleh variabel lain di luar model penelitian ini.

2. Analisis Regresi Model II

Model regresi persamaan II menganalisis pengaruh lingkungan kerja dan kompensasi terhadap kinerja. Hasil uji F pada model regresi persamaan II dapat dilihat pada tabel berikut. 
Tabel 4

Uji F Persamaan II

\begin{tabular}{|ll|r|r|r|r|r|}
\hline \multicolumn{2}{|l|}{ Model } & \multicolumn{1}{|c|}{$\begin{array}{c}\text { Sum of } \\
\text { Squares }\end{array}$} & df & \multicolumn{1}{c|}{$\begin{array}{c}\text { Mean } \\
\text { Square }\end{array}$} & F & \multicolumn{1}{c|}{ Sig. } \\
\hline 1 & Regression & 219.145 & 2 & 109.573 & 5.254 & $.007 \mathrm{a}$ \\
& Residual & 1522.539 & 73 & 20.857 & & \\
& Total & 1741.684 & 75 & & & \\
\hline
\end{tabular}

Sumber: data primer diolah, 2017

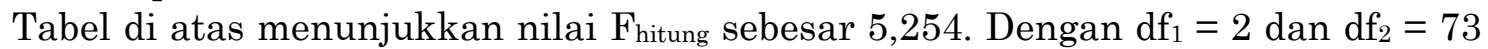
serta $\alpha=5 \%$, diperoleh $F_{\text {tabel }}$ sebesar 3,13. Dengan demikian $F_{\text {hitung }}>F_{\text {tabel }}(5,25>3,13)$. Dengan demikian H3 diterima. Hasil uji t pada model regresi persamaan II dapat dilihat pada tabel berikut.

Tabel 5

Uji t Persamaan II

\begin{tabular}{|c|c|c|c|c|c|c|}
\hline \multirow{2}{*}{\multicolumn{2}{|c|}{ Model }} & \multicolumn{2}{|c|}{$\begin{array}{c}\text { Unstandardized } \\
\text { Coefficients }\end{array}$} & \multirow{2}{*}{\begin{tabular}{|c|}
$\begin{array}{c}\text { Standardized } \\
\text { Coefficients }\end{array}$ \\
Beta
\end{tabular}} & \multirow[b]{2}{*}{$\mathrm{t}$} & \multirow[b]{2}{*}{ Sig. } \\
\hline & & B & Std. Error & & & \\
\hline \multirow[t]{3}{*}{1} & (Constant) & 32.775 & 4.410 & & 7.432 & .000 \\
\hline & $\begin{array}{l}\text { lingkungan } \\
\text { kerja }\end{array}$ & .116 & .071 & .191 & 1.642 & .105 \\
\hline & kompensasi & .227 & .109 & .242 & 2.079 & .041 \\
\hline
\end{tabular}

Sumber: data primer diolah, 2017

Tabel di atas menunjukkan nilai thitung variabel lingkungan kerja sebesar 1,642 dan kompensasi sebesar 2,079. Dengan $\mathrm{df}=73$ dan $\alpha=5 \%$ diperoleh t tabel sebesar 1,99. Berikut ini analisis dari masing-masing variabel independen:

1. Pengaruh lingkungan kerja terhadap kinerja

Hasil uji t menunjukkan bahwa thitung sebesar 1,642 dan nilai signifikansi sebesar 0,105 . Hasil tersebut menunjukkan bahwa nilai thitung $(1,642)<t_{\text {tabel }}(1,99)$ dan atau $p$ value $0,105>0,05$ maka dapat disimpulkan bahwa lingkungan kerja tidak berpengaruh terhadap kinerja karyawan.

2. Pengaruh kompensasi terhadap kinerja karyawan

Hasil uji t menunjukkan bahwa thitung sebesar 2,079 dan nilai signifikansi sebesar 0,041 . Hasil tersebut menunjukkan bahwa nilai thitung $(2,079)>t_{\text {tabel }}(1,99)$ dan atau $p$ value $0,041<0,05$ maka dapat disimpulkan bahwa kompensasi berpengaruh positif terhadap kinerja karyawan.

Berdasarkan kedua analisis di atas dapat disimpulkan bahwa hanya kompensasi yang berpengaruh positif terhadap motivasi kerja karyawan "Yogya Chicken" di Daerah Istimewa Yogyakarta secara parsial.

Untuk mengetahui besarnya pengaruh variabel lingkungan kerja dan kompensasi terhadap kinerja karyawan "Yogya Chicken" di Daerah Istimewa Yogyakarta dapat dilihat pada tabel di bawah ini.

Tabel 6

Hasil Uji Koefisien Determinasi 


\begin{tabular}{|l|l|r|r|r|}
\hline Model & R & R Square & $\begin{array}{c}\text { Adjusted R } \\
\text { Square }\end{array}$ & $\begin{array}{c}\text { Std. Error of } \\
\text { the Estimate }\end{array}$ \\
\hline 1 & 0,355 & 0,126 & 0,102 & 4,567 \\
\hline
\end{tabular}

Sumber: data primer diolah

Tabel di atas menunjukkan nilai koefisien determinasi $\left(\mathrm{R}^{2}\right)$ sebesar 0,126. Artinya pengaruh variabel lingkungan kerja dan kompensasi terhadap kinerja karyawan sebesar $12,6 \%$ sedangkan $87,4 \%$ dipengaruhi oleh variabel lain di luar model penelitian ini.

3. Analisis Regresi Model III

Model regresi persamaan III menganalisis pengaruh lingkungan kerja, kompensasi dan motivasi kerja terhadap kinerja. Hasil uji F pada model regresi persamaan III dapat dilihat pada tabel berikut.

Tabel 7

Uji F Persamaan III

\begin{tabular}{|c|c|c|c|c|c|c|}
\hline \multicolumn{2}{|c|}{ Model } & $\begin{array}{l}\text { Sum of } \\
\text { Squares }\end{array}$ & $\mathrm{df}$ & $\begin{array}{l}\text { Mean } \\
\text { Square }\end{array}$ & $\mathrm{F}$ & Sig. \\
\hline \multirow[t]{3}{*}{1} & Regression & 404,452 & 3 & \multirow{3}{*}{$\begin{array}{r}134,817 \\
18,573\end{array}$} & \multirow[t]{3}{*}{7,259} & \multirow[t]{3}{*}{0,000} \\
\hline & Residual & 1337,232 & 72 & & & \\
\hline & Total & 1741,684 & 75 & & & \\
\hline
\end{tabular}

Sumber: data primer diolah, 2017

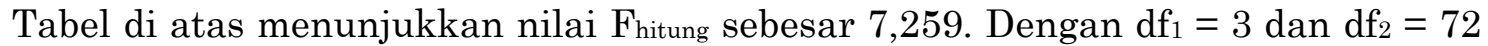
serta $\alpha=5 \%$, diperoleh $F_{\text {tabel }}$ sebesar 2,74. Dengan demikian $F_{\text {hitung }}>F_{\text {tabel }}(7,259>$ 2,74).Hasil uji t pada model regresi persamaan III dapat dilihat pada tabel berikut.

Tabel 8

Uji t Persamaan III

\begin{tabular}{|c|c|c|c|c|c|}
\hline \multirow[b]{2}{*}{ Model } & \multicolumn{2}{|c|}{$\begin{array}{c}\text { Unstandardized } \\
\text { Coefficients }\end{array}$} & \multirow{2}{*}{\begin{tabular}{|c|}
$\begin{array}{c}\text { Standardized } \\
\text { Coefficients }\end{array}$ \\
Beta \\
\end{tabular}} & \multirow[b]{2}{*}{$\mathrm{t}$} & \multirow[b]{2}{*}{ Sig. } \\
\hline & $\mathrm{B}$ & Std. Error & & & \\
\hline $1 \quad$ (Constant) & 32,132 & 4,167 & & 7,712 & 0,000 \\
\hline $\begin{array}{l}\text { lingkungan } \\
\text { kerja }\end{array}$ & 0,066 & 0,088 & 0,109 & 0,749 & 0,456 \\
\hline kompensasi & 0,068 & 0,115 & 0,073 & 0,595 & 0,554 \\
\hline motivasi & 0,236 & 0,075 & 0,509 & 3,159 & 0,002 \\
\hline
\end{tabular}

Sumber: data primer diolah, 2017

Tabel di atas menunjukkan nilai thitung variabel lingkungan kerja sebesar 0,749, kompensasi sebesar 0,595 dan motivasi kerja sebesar 3,159. Dengan df $=72$ dan $\alpha=5 \%$ diperoleh tabel sebesar 1,99. Berikut ini analisis dari masing-masing variabel independen: 1. Pengaruh lingkungan kerja terhadap kinerja karyawan

Hasil uji t menunjukkan bahwa thitung sebesar 0,749 dan nilai signifikansi sebesar 0,456 . Hasil tersebut menunjukkan bahwa nilai thitung $(0,749)<t_{\text {tabel }}(1,99)$ dan atau $p$ 
value 0,456 > 0,05 maka dapat disimpulkan bahwa lingkungan kerja tidak berpengaruh terhadap kinerja karyawan.

2. Pengaruh kompensasi terhadap kinerja karyawan

Hasil uji t menunjukkan bahwa thitung sebesar 0,595 dan nilai signifikansi sebesar 0,554 . Hasil tersebut menunjukkan bahwa nilai thitung $(0,595)<$ tabel $(1,99)$ dan atau $p$ value $0,554>0,05$ maka dapat disimpulkan bahwa kompensasi tidak berpengaruh terhadap kinerja karyawan.

3. Pengaruh motivasi kerja terhadap kinerja karyawan

Hasil uji t menunjukkan bahwa thitung sebesar 3,159 dan nilai signifikansi sebesar 0,002 . Hasil tersebut menunjukkan bahwa nilai thitung $(3,159)>t_{\text {tabel }}(1,99)$ dan atau $p$ value $0,002<0,05$ maka dapat disimpulkan bahwa motivasi kerja berpengaruh positif terhadap kinerja karyawan.

Berdasarkan ketiga analisis di atas dapat disimpulkan bahwa hanya motivasi kerja yang berpengaruh positif terhadap kinerja karyawan "Yogya Chicken" di Daerah Istimewa Yogyakarta secara parsial. Untuk mengetahui besarnya pengaruh variabel lingkungan kerja, kompensasi dan motivasi kerja terhadap kinerja karyawan "Yogya Chicken” di Daerah Istimewa Yogyakarta dapat dilihat pada tabel di bawah ini.

Tabel 9

Hasil Uji Koefisien Determinasi

\begin{tabular}{|l|c|r|r|r|}
\hline Model & R & R Square & $\begin{array}{c}\text { Adjusted R } \\
\text { Square }\end{array}$ & $\begin{array}{r}\text { Std. Error of } \\
\text { the Estimate }\end{array}$ \\
\hline 1 & 0,482 & 0,232 & 0,200 & 4,310 \\
\hline
\end{tabular}

Sumber: data primer diolah

Tabel di atas menunjukkan nilai koefisien determinasi $\left(\mathrm{R}^{2}\right)$ sebesar 0,232 . Artinya pengaruh variabel lingkungan kerja, kompensasi dan motivasi kerja terhadap kinerja karyawan sebesar $23,2 \%$ sedangkan $76,8 \%$ dipengaruhi oleh variabel lain di luar model penelitian ini.

\section{Pembahasan}

1. Pengaruh Secara Simultan Antara Lingkungan Kerja Dan Kompensasi Terhadap Motivasi Kerja Karyawan Rumah Makan "Yogya Chicken"

Berdasarkan hasil analisis diperoleh nilai Fhitung $>$ Ftabel $(52,23>3,13)$, yang berarti secara simultan lingkungan kerja dan kompensasi berpengaruh signifikan terhadap motivasi kerja karyawan. Lingkungan kerja fisik dan non fisik yang terkelola dengan baik akan mampu membuat suasana kerja menjadi nyaman sehingga mampu membuat para karyawan menjadi lebih termotivasi untuk bekerja lebih baik.

2. Pengaruh Secara Parsial antara Lingkungan Kerja dan Kompenssi terhadap Motivasi Kerja Karyawan

Berdasarkan hasil analisis regresi linier berganda diperoleh thitung $>$ ttabel $(7,383$ $>1,99$ ), yang berarti lingkungan kerja berpengaruh positif terhadap motivasi kerja. Artinya semakin nyaman lingkungan kerja perusahaan maka akan semakin tinggi juga motivasi kerja karyawan, sebaliknya semakin tidak nyaman lingkungan kerja maka motivasi kerja karyawan juga akan turun.

Berdasarkan hasil analisis regresi linier berganda diperoleh $t_{\text {hitung }}>t_{\text {tabel }}(4,168>$ 1,99), yang berarti kompensasi berpengaruh positif terhadap motivasi kerja. Artinya semakin tinggi kompensasi yang diterima karyawan maka akan semakin tinggi juga 
motivasi kerja karyawan, sebaliknya semakin rendah kompensasi yang diterima karyawan maka motivasi kerja karyawan juga akan rendah.

3. Pengaruh Secara Simultan Lingkungan Kerja dan Kompensasi terhadap Kinerja Karyawan

Berdasarkan hasil analisis diperoleh nilai Fhitung $>$ Ftabel $(5,25>3,13)$, yang berarti secara simultan lingkungan kerja dan kompensasi berpengaruh signifikan terhadap kinerja karyawan. Artinya, semakin baik kondisi lingkungan kerja dan didukung dengan semakin tingginya kompensasi maka akan meningkatkan kinerja karyawan. Sebaliknya, kondisi lingkungan kerja yang kurang baik ditambah dengan kompensasi yang rendah maka dapat menurunkan kinerja karyawan.

4. Pengaruh Secara Parsial Lingkungan Kerja dan Kompensasi terhadap Kinerja Karyawan

Berdasarkan hasil analisis menunjukkan bahwa lingkungan kerja tidak berpengaruh signifikan terhadap kinerja karyawan. Ditunjukkan oleh $t_{\text {hitung }}<t_{\text {tabel }}(1,642$ $<1,99$ ). Hal ini berarti lingkungan kerja bukan merupakan faktor utama yang mempengaruhi kinerja karyawan. Tidak signifikannya pengaruh lingkungan kerja terhadap kinerja karyawan RM "Yogya Chicken" disebabkan karena karyawan sudah mampu menyesuaikan diri dengan kondisi lingkungan perusahaan, karena telah lama bekerja di Rumah Makan "Yogya Chicken". Selain itu, karyawan lebih mengedepankan kenyamanan kepada pelanggan dalam bentuk ruang makan yang luas, daripada ruang kerja untuk karyawan itu sendiri.

Berdasarkan hasil analisis regresi linier berganda diperoleh $t_{\text {hitung }}>t_{\text {tabel }}(2,079>$ 1,99), yang berarti kompensasi berpengaruh positif terhadap kinerja karyawan. Artinya semakin tinggi kompensasi yang diterima karyawan maka akan semakin tinggi juga kinerja karyawan, sebaliknya semakin rendah kompensasi yang diterima karyawan maka kinerja karyawan juga akan menurun.

\section{Pengaruh Motivasi Kerja terhadap Kinerja Karyawan}

Berdasarkan hasil analisis menunjukkan bahwa motivasi kerja berpengaruh signifikan terhadap kinerja karyawan. Ditunjukkan oleh bahwa nilai thitung $(3,159)>t_{\text {tabel }}$ $(1,99)$. Artinya semakin tinggi motivasi kerja maka akan semakin tinggi juga kinerja karyawan. Sebaliknya semakin rendah motivasi kerja maka akan semakin rendah juga kinerja karyawan.

6. Pengaruh secara Simultan Lingkungan Kerja, Kompensasi, dan Motivasi Kerja terhadap Kinerja Karyawan

Berdasarkan hasil analisis diperoleh nilai Fhitung $>$ Ftabel $(7,259>2,74)$, artinya secara simultan lingkungan kerja, kompensasi dan motivasi kerja berpengaruh signifikan terhadap kinerja karyawan. Semakin baik lingkungan kerja dan semakin tinggi kompensasi yang diterima karyawan serta ditunjang oleh motivasi kerja yang tinggi maka kinerja karyawan juga akan tinggi. Sebaliknya, semakin tidak baik lingkungan kerja dan semakin rendah kompensasi yang diterima dan karyawan yang mempunyai motivasi kerja rendah maka kinerja karyawan juga akan turun.

7. Pengaruh secara Parsial Lingkungan Kerja, Kompensasi, dan Motivasi Kerja terhadap Kinerja Karyawan

Berdasarkan hasil analisis pada model persamaan regresi III diperoleh nilai nilai $t_{\text {hitung }}(-0,749)<t_{\text {tabel }}(1,99)$, yang berarti lingkungan kerja tidak berpengaruh signifikan terhadap kinerja karyawan. Berdasarkan hasil analisis pada model persamaan regresi III juga menunjukkan bahwa kompensasi tidak berpengaruh terhadap kinerja karyawan. Ditunjukkan oleh thitung $(0,595)<t_{\text {tabel }}(1,99)$. Hal ini mengindikasikan bahwa kompensasi tidak memberikan pengaruh yang nyata terhadap kinerja karyawan. Hasil ini berbeda 
dengan hasil pada persamaan regresi model II yang menunjukkan bahwa kompensasi berpengaruh terhadap kinerja karyawan. Perbedaan ini disebabkan karena pada model persamaan regresi III dimasukan variabel motivasi sebagai variabel independen, sedangkan pada persamaan regresi II tidak ada variabel motivasi. Dengan demikian variabel motivasi tidak mampu memoderasi hubungan antara kompensasi dengan kinerja karyawan atau motivasi tidak mampu memperkuat hubungan antara kompensasi terhadap kinerja karyawan. Dengan kata lain, kompensasi mampu meningkatkan kinerja karyawan, walaupun tanpa adanya motivasi kerja.

Berdasarkan hasil analisis pada persamaan regresi III diperoleh hasil bahwa motivasi kerja berpengaruh signifikan terhadap kinerja karyawan. Ditunjukkan oleh nilai $t_{\text {hitung }}(3,159)>t_{\text {tabel }}(1,99)$. Artinya semakin tinggi motivasi kerja maka kinerja pegawai juga akan semakin tinggi.

\section{PENUTUP}

Berdasarkan hasil analisis dan pembahasan pada bab sebelumnya, maka dapat disimpulkan sebagai berikut;

1. Secara simultan lingkungan kerja, dan kompensasi berpengaruh positif terhadap motivasi kerja karyawan "Yogya Chicken" di Daerah Istimewa Yogyakarta.

2. Secara parsial lingkungan kerja dan kompensasi berpengaruh positif terhadap motivasi kerja karyawan "Yogya Chicken" di Daerah Istimewa Yogyakarta

3. Secara simultan lingkungan kerja dan kompensasi berpengaruh positif terhadap kinerja karyawan "Yogya Chicken" di Daerah Istimewa Yogyakarta.

4. Secara parsial lingkungan kerja tidak berpengaruh terhadap kinerja karyawan "Yogya Chicken" di Daerah Istimewa Yogyakarta, sedangkan kompensasi berpengaruh positif terhadap kinerja karyawan "Yogya Chicken" di Daerah Istimewa Yogyakarta.

5. Motivasi kerja berpengaruh positif terhadap kinerja karyawan "Yogya Chicken" di Daerah Istimewa Yogyakarta.

6. Secara simultan lingkungan kerja, kompensasi dan motivasi kerja berpengaruh positif terhadap kinerja karyawan "Yogya Chicken" di Daerah Istimewa Yogyakarta.

Secara parsial lingkungan kerja dan kompensasi tidak berpengaruh terhadap kinerja karyawan, sedangkan motivasi kerja berpengaruh positif terhadap kinerja karyawan

\section{REFERENSI}

Crimsom, Sitanggang., 2005, Analisis Pengaruh Perilaku Pemimpin Terhadap Kinerja Pegawai pada Sekertariat Kotamadya Jakarta Barat, Skripsi, UNDIP, Semarang

Hasan, Iqbal, 2005, Pokok-Pokok Materi Statistik 2 (Statistik Inferensif, Edisi Kedua, Bhumi Aksara, Jakarta.

Handoko, Hani, 2001, Manajemen Personalia dan Sumberdaya Manusia, Edisi Kedua, BPFE Yogyakarta

Handoko, Hani, 2005, Manajemen Personalia dan Sumberdaya Manusia, BPFE Yogyakarta

Hasibuan, Malayu, 2005, Manajemen Sumber Daya Manusia, Edisi Revisi, Bumi Aksara, Jakarta

Kreitner, R, Kinicki, A.,1995, Organizational Behavior. Third Edition, Printed in The United State of America: Richard D Irwin Inc 
Mangkunegara, AP., 2011, Manajemen Sumber Daya Manusia Perusahaan, PT RemajaRosdakarya, Bandung.

Maslow, Abraham., 1996, Motivasi dan Kepribadian, Midas Surya Grafindo, Jakarta

Mondy, R.W dan R.M. Noe 1990, Human Resource Management. Pearson Education International, New Jersey

Mosley, R., 1996, Employer Branding, John Wiley \& Sons

Nuraini, T., 2013, Manajemen Sumber Daya Manusia, yayasan Aini Syam, Pekanbaru

Noe, Raymond A., 2002, Employee Training \& Development, Mc Graw Hill, New York

Robbins, S., 2008, Organizational Behaviour, Alih Bahasa Drs. Benyamin Molan, Macanan Jaya Cemerlang, Jakarta

Robert Heller, 1998, Motivating People, Dorling Kindersley, London

Sastrohadiwiryo, 2002, Manajemen Tenaga Kerja Indonesia Pendekatan Administrasi dan Operasional, Bumi Aksara, Jakarta

Werther \&, Davis, K., 1996, Human Resources And Personnel Management. Singapore: McGraw-Hill Book, Co 